\title{
"Something smells fishy": food borne illness in an international ship crew in St. John, NB
}

\author{
Submitted by Office of the Chief Medical Officer of Health \\ As published in the New Brunswick Disease Watch Bulletin - Volume 21 (reprinted with permission; original available at http://www2.gnb.ca/ \\ content/dam/gnb/Departments/h-s/pdf/en/Publications/NBDiseaseWatchBulletin_vol21.pdf, pp. 2-4.)
}

\section{Case presentation}

On April 11, 2015, nine male crew members of an international cargo vessel docked in Saint John presented to the Emergency room at the Saint John Regional Hospital (SJRH) with gastrointestinal symptoms (nausea, vomiting, diarrhea, abdominal cramps). Other significant symptoms included dizziness, weakness and peripheral extremity parasthesias. When examined, several of them were further found to have hypotension and bradycardia. All were admitted for intensive care level monitoring and management, including continuous cardiac monitoring, atropine for bradycardia, antiemetics, and intravenous rehydration. Shortly thereafter, five more crew members presented with the same symptoms and were also admitted. The crew members reported that they had consumed a common meal of fish stew using fish they had caught during their voyage in the Caribbean, and had begun feeling ill 1-1.5 hours afterwards. The attending physicians consulted with the Poison Control centre in Halifax and identified ciguatera fish poisoning as the most likely diagnosis. The incident was reported to Public Health. A Code Orange was initiated by the SJRH to manage this large influx of critically ill patients.

\section{Investigation}

In New Brunswick, clinicians are required to report clusters of illness thought to be food or waterborne immediately (verbally within one hour) to their regional Public Health office. There is also a requirement to report unusual illness (not expected to occur in $\mathrm{NB}$ or unknown etiology) within 24 hours. Investigation of this incident was conducted jointly by New Brunswick Public Health staff (Health Protection Branch, Department of Health) and Environmental Health Officers from the Public Health Agency of Canada's Travelling Public Program.

The galley kitchen was closed until a full inspection was conducted and remaining crew obtained food off ship during that time. Remaining crew members were briefly monitored until it could be firmly established that there were no remaining susceptible individuals. There were $19 \mathrm{crew}$ members onboard the cargo vessel when the outbreak occurred, of which fourteen $(73.7 \%)$ had eaten the suspect meal of fish soup. The five remaining crew were either sleeping or ate the alternative pork meal that was served. All crew that ate the fish meal were ill and required admission to hospital for intensive care level monitoring and management. The average length of stay was 3.5 days and one individual required a readmission for continued symptoms. Following discharge, the crew members were repatriated by the ship owners as several of them were considered to be "unfit for duty" by attending physicians.

The severity of symptoms directly correlated with the amount of fish soup that was consumed and what part of the fish was ingested. For example, the individual who experienced the most severe symptoms ate the largest portion of the meal including the head of the fish.

Further questioning revealed that the crew had line fished off the boat while anchored in the Bahamas and had caught more than 125 kilos of fish in this manner. The fish was separated and frozen intact for crew consumption, and portions were eaten daily during their voyage north to Saint John, NB. While at port in Saint John one of the larger fish was thawed then prepared by removing entrails, gills, and fins, descaled, and then cooked in a fish soup with the head still attached.

Samples of fish left over from the suspect meal and samples of frozen fish that were also caught in the Bahamas were sent to the Canadian Food Inspection Agency Laboratory (Dartmouth) for species analysis and toxin testing. The fish stew specimen was reported as "suspected positive" for ciguatoxin (due to lack of analytical standards the lab is unable to quantify the concentration of ciguatoxin in the sample). The remaining fish on the ship that was unlabelled or obtained from an unapproved food supplier was soaked in a strong sodium hypochlorite solution to render it inconsumable and then disposed (Public Health Agency of Canada. Environmental Health Report. New Brunswick: Traveling Public Program; 2015 unpublished report).

\section{Ciguatera fish poisoning}

Ciguatera is a foodborne illness that is caused by eating reef fish contaminated with a toxin called "ciguatoxin". Ciguatoxin is colorless, odourless and tasteless, and the fish are not altered in appearance. The toxin cannot be destroyed by cooking, smoking, freezing, canning, salting or drying. This poison is produced by dinoflagellates: small organisms that attach to algae growing in warm ocean reef areas. Small plant eating fish ingest these toxic algae and are then eaten by larger predatory 
fish, which are in turn consumed by humans (Government of Canada). Fish in affected areas are not uniformly impacted, so it is possible for only a few fish out of any given catch to contain sufficient levels of toxin to cause illness. The toxin is lipid- soluble and concentrates in the head, viscera and roe of the fish (Centers for Disease Control and Prevention, 1998).

Symptoms of ciguatera fish poisoning can occur within minutes, but generally develop within 24 hours of eating contaminated fish. Initial gastrointestinal symptoms include nausea, vomiting, diarrhea and abdominal pain. These symptoms may last several days. Neurological symptoms develop after the initial gastrointestinal symptoms, and include tingling and numbness around the mouth, lips, throat, arms and legs, sore muscles and tooth pain, temperature reversal (hot things feel cold and cold things feel hot), feeling tired, headaches and itchy skin. In severe cases, neurological symptoms can last months or longer and may be worsened by changes in dietary behaviour (such as dieting or high protein meals), alcohol consumption, exercise or sexual intercourse (Centers for Disease Control and Prevention, 1998). Most people suffering from ciguatera fish poisoning will recover completely within a few days or weeks, but in very rare cases, ciguatera can be fatal (Government of Canada).

Diagnosis is based on astute recognition of the clinical presentation and compatible food exposure history - no human diagnostic testing is currently available. However, stool specimens should be routinely collected to rule out other more common causes of food borne intoxications. If food specimens are available they can be collected and tested for presence of ciguatera toxin. There is no antidote for ciguatera poisoning, and people who have consumed ciguatoxin receive symptomatic treatment (Schlaich et al., 2012).

Prevention relies on public and industry awareness of ciguatera affected areas and fish species (in particular, large predatory warm water fish), since ciguatera toxic fish are not easily detected and no known preparation method can remove or destroy the toxin.

\section{References}

Centers for Disease Control and Prevention. 1998. Morbidity and mortality weekly report: Ciguatera fish poisoning - Texas, 1997. Georgia: Centers for Disease Control and Prevention. Available at: http://www.cdc.gov/mmwr/preview/mmwrhtml/00054548.htm

Government of Canada. Available at: http://travel.gc.ca/travelling/ health-safety/diseases/ciguatera

Schlaich, C., Hagelstein, J.-G., Burchard, G.-D., and Schmiedel, S. 2012. Outbreak of ciguatera fish poisoning on a cargo ship in the port of Hamburg. J. Travel Med., 19(4): 238-242. PMID: 22776385. doi: $10.1111 /$ j.1708-8305.2012.00619.x 